\title{
Endoscopic endonasal approach for craniovertebral junction pathology: a review of the literature
}

\author{
Saul F. Morales-Valero, MD, ${ }^{1}$ Elena Serchi, MD, ${ }^{2}$ Matteo Zoli, MD, ${ }^{2}$ Diego Mazzatenta, MD, ${ }^{2}$ and \\ Jamie J. Van Gompel, MD' \\ 'Department of Neurologic Surgery, Mayo Clinic, Rochester, Minnesota; and 2Department of Neurosurgery, IRCCS Institute of \\ Neurological Sciences, Bellaria Hospital, Bologna, Italy
}

\begin{abstract}
OBJECT The transoral approach is the gold standard for ventral decompression of the brainstem caused by craniovertebral junction (CVJ) pathology. This approach is often associated with significant morbidity, related to swallowing and respiratory complications. The endoscopic endonasal approach was introduced to reduce the rate of these complications. However, the exact role of this approach in the treatment of CVJ pathology is not well defined.

METHODS A comprehensive literature search was performed to identify series of patients with pathology of the CVJ treated via the endoscopic endonasal approach. Data on patient characteristics, indications for treatment, complications, and outcome were obtained and analyzed.

RESULTS Twelve studies involving 72 patients were included. The most common indications for treatment were rheumatoid pannus (38.9\%) and basilar invagination (29.2\%). Cerebrospinal fluid leak was found in $18 \%$ of cases intraoperatively and $4.2 \%$ of cases postoperatively. One case of meningitis complicated by sepsis and death represents the procedure-related mortality of $1.4 \%$. Of the patients without preoperative swallowing impairment, $95 \%$ returned to oral feeding on the 3rd postoperative day. Ninety-three percent of patients experienced improvement in neurological symptoms after the procedure.

CONCLUSIONS The endonasal endoscopic approach is effective for the treatment of neural compression caused by CVJ pathology. It offers advantages such as lower rates of postoperative dysphagia and respiratory complications when compared with the more traditional transoral approach. However, these 2 approaches should be seen as complementary rather than alternatives. Patient-related factors as well as the surgeon's expertise must be considered when making treatment decisions.
\end{abstract}

http://thejns.org/doi/abs/10.3171/2015.1.FOCUS14831

KEY WORDS craniovertebral junction; endoscopic surgery; odontoidectomy; basilar invagination

$\mathrm{T}$ HE microsurgical transoral approach is the traditional route and technique used for surgical treatment of ventral compression of the brainstem. Limitations of the transoral approach include the need for a direct oropharyngeal incision to access the odontoid with potential delayed enteral nutrition. In 2002, Alfieri and colleagues performed an anatomical study and demonstrated that the ventral craniovertebral junction (CVJ) could be effectively exposed through an endoscopic endonasal approach. ${ }^{1}$
With refinements of endoscopic endonasal techniques, in 2005 Kassam and colleagues reported on a patient with ventral brainstem compression due to a rheumatoid pannus who underwent a successful operation via a completely endoscopic endonasal approach. ${ }^{9}$ Since then, isolated case reports and case series have been reported. However, the exact role of the endoscopic endonasal approach for the treatment of CVJ pathology remains controversial. In the present study, we performed a review of published se-

ABBREVIATION CVJ = craniovertebral junction.

SUBMITTED December 1, 2014. ACCEPTED January 19, 2015.

INCLUDE WHEN CITING DOI: 10.3171/2015.1.FOCUS14831.

DISCLOSURE The authors report no conflict of interest concerning the materials or methods used in this study or the findings specified in this paper. 
ries of patients treated through the endoscopic endonasal route and discuss its potential role in the treatment of these challenging lesions.

\section{Methods}

A comprehensive literature search of several databases indexing English-language literature published from 1990 to November 13, 2014, was conducted. The databases included Ovid MEDLINE In-Process \& Other Non-Indexed Citations, Ovid MEDLINE, Ovid EMBASE, Ovid Cochrane Central Register of Controlled Trials, Ovid Cochrane Database of Systematic Reviews, Scopus, and Web of Science. The search strategy was designed and conducted by an experienced librarian with input from the authors. Controlled vocabulary supplemented with keywords was used to search for studies of the endoscopic endonasal approach to the CVJ. The actual strategy is available from the corresponding author.

All studies reporting on patients who were treated surgically using an endoscopic endonasal approach were selected. Inclusion criteria were the following: series of 3 or more patients with available data on indications for treatment, procedure-related complications, and clinical outcomes. To avoid duplication of patients, when multiple papers were found from the same authors or the same institution, only the report with the largest relevant cohort was included. Two reviewers (S.F.M.V. and E.S.) independently selected the included studies. A manual search for studies was also conducted by screening references from the identified papers and in major neurosurgical journals.

For each study, we extracted the following information: patients' demographic characteristics, presentation, etiopathology, perioperative complications, time to extubation and oral feeding as well as immediate and longterm neurological outcome. Good neurological outcome was determined if the study used terms such as "no morbidity," "improvement," or "good recovery." The primary objective of this study was to determine the effectiveness as well as the rate of systemic and neurological complications after endonasal endoscopic treatment of pathology involving the CVJ.

\section{Results \\ Search Results and Study Characteristics}

The search criteria led to 265 citations, and 1 recently published study was identified through our manual search? After screening the titles and abstracts, we identified 45 articles about endoscopic approaches to the CVJ, and the full texts were reviewed carefully. Of these 45 articles, 32 did not meet the inclusion criteria: 7 were anatomical studies, 4 were imaging studies, 7 studies dealt with the endoscopic transoral approach, 2 were review articles, 10 were individual case reports, and 2 included 2 patients only. A total of 13 studies included patients with CVJ pathology treated using an endoscopic endonasal approach and met our inclusion criteria. Two publications corresponded to the same group, ${ }^{6,8}$ and only the most recent was included. A total of 12 studies comprising 72 patients were included in our analysis ${ }^{2,4-7,10-13,17,19,20}$ (Fig. 1 and Table 1). All studies provided data on patient demographics, clinical presentation, indications for treatment, periprocedural complications, and neurological outcome.

\section{Patient Characteristics}

Patient characteristics are summarized in Table 2. The mean patient age was 55.8 years (range 6-96 years), and $57.1 \%$ of patients were female. The most common indications for treatment were rheumatoid pannus $(38.9 \%)$ and basilar invagination $(29.2 \%)$ causing compression of the cervicomedullary junction. The most common presenting symptoms were myelopathy, present in $77.8 \%$ of patients and neck pain, reported in $30.6 \%$. Swallowing disturbance was seen in $15.3 \%$ of cases preoperatively.

\section{Complications and Outcome}

Intraoperative CSF leak was reported in 13 cases (18\%). However, it was present in only 3 patients $(4.2 \%)$ postoperatively. One patient developed meningitis that was complicated by sepsis and death, resulting in a procedure-related mortality of $1.4 \%$. Transient velopharyngeal insufficiency was seen in 3 cases (4.2\%), and 2 patients had respiratory failure in the perioperative period.

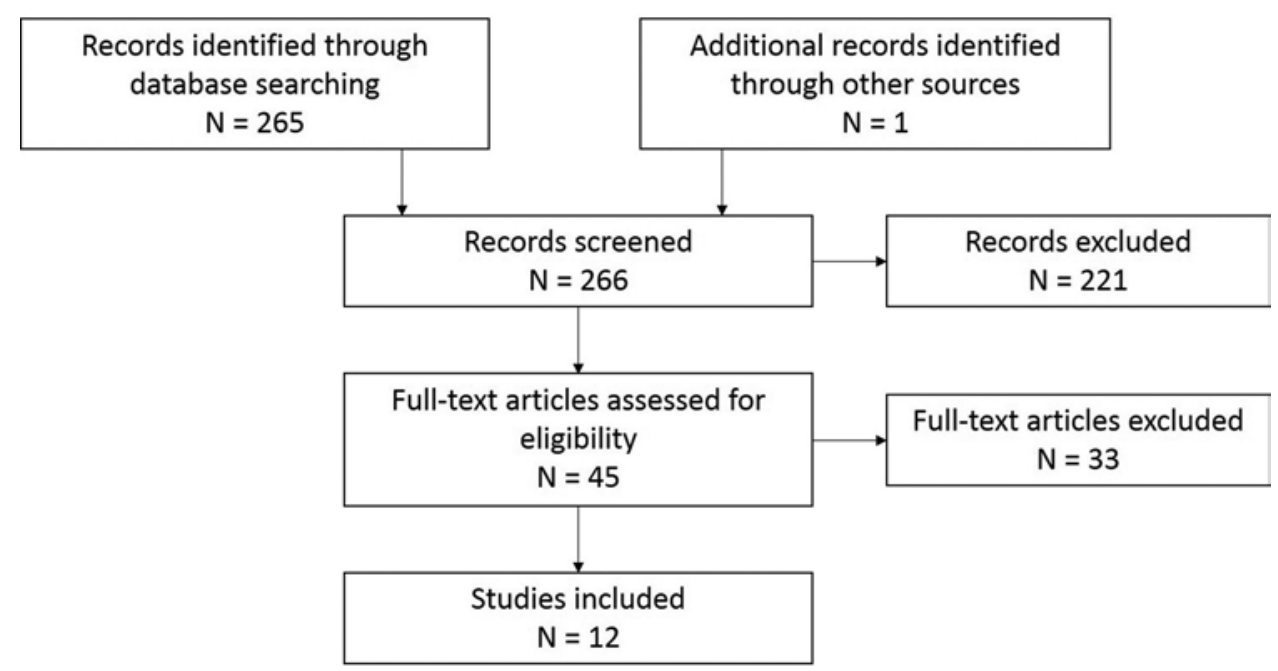

FIG. 1. Flow diagram showing the review process. 
TABLE 1. Characteristics of studies included in the literature review

\begin{tabular}{llcccc}
\hline \multicolumn{1}{c}{ Authors \& Year } & Study Design & No. of Patients & No. of Females & Mean Age (yrs) & Mean Follow-Up (mos) \\
\hline Goldschlager et al., 2015 & Retrospective & 9 & 5 & 45 & 42.9 \\
\hline Mazzatenta et al., 2014 & Retrospective & 5 & 3 & 30 & 34.2 \\
\hline Ponce-Gómez et al., 2014 & Retrospective & 5 & 4 & 42.6 & 6 \\
\hline Duntze et al., 2014 & Retrospective & 9 & 4 & 63.7 & 6 \\
\hline Choudhri et al., 2014 & Retrospective & 5 & 4 & 67.4 & 18.8 \\
\hline Yen et al., 2014 & Retrospective & 13 & 7 & 52.7 & 55.5 \\
\hline Yu et al., 2013 & Retrospective & 3 & 2 & 51.3 & 26.7 \\
\hline Gladi et al., 2012 & Retrospective & 4 & 3 & 74.3 & 22 \\
\hline Gempt et al., 2011 & Retrospective & 3 & 3 & 64.3 & 6.3 \\
\hline Lee et al., 2010 & Retrospective & 4 & 1 & 48.8 & 4.7 \\
\hline Wu et al., 2008 & Retrospective & 3 & 0 & 44.3 & 1 \\
\hline Nayak et al., 2007 & Retrospective & 9 & NA & 75.8 & 3 \\
\hline
\end{tabular}

$\mathrm{NA}=$ not available.

Data on time to extubation were available for 49 patients; 1 patient was ventilator dependent preoperatively and remained intubated after the surgical procedure. Of the remaining 48 patients, 27 were extubated the day of the procedure and 20 on the 1st postoperative day. One patient with severe quadriparesis remained intubated for 1 week until posterior fixation was performed due to the high risk of respiratory failure. A total of 63 patients had available data on time to oral feeding. Three patients had significant preoperative dysphagia requiring nasogastric

TABLE 2. Patient characteristics*

\begin{tabular}{cc}
\hline \multicolumn{1}{c}{ Variable } & Value \\
\hline Demographic characteristics & \\
\hline Age in yrs & $55.8 \pm 20.8$ \\
\hline Mean \pm SD & $6-96$ \\
\hline Range & 57.1 \\
\hline$\%$ female & \\
\hline Presenting symptoms & $56(77.8)$ \\
\hline Myelopathy & $22(30.6)$ \\
\hline Neck pain & $11(15.3)$ \\
\hline Swallowing disturbance & $1(1.4)$ \\
\hline Bulbar involvement & $1(1.4)$ \\
\hline Asymptomatic & \\
\hline Pathological condition & $28(38.9)$ \\
\hline Rheumatoid pannus & $21(29.2)$ \\
\hline Basilar invagination & $5(6.9)$ \\
\hline Os odontoideum & $6(6.9)$ \\
\hline Tumor & $4(5.6)$ \\
\hline Atlantoaxial subluxation & $4(5.6)$ \\
\hline Trauma & $2(2.8)$ \\
\hline Skull base osteomyelitis & $1(1.4)$ \\
\hline Atlas assimilation & $1(1.4)$ \\
\hline Ganglion cyst & $1(1.4)$ \\
\hline Gout &
\end{tabular}

* Values are reported as the number of patients (\%) unless otherwise indicated. tube feeding, which was continued postoperatively. Of the 60 patients with adequate swallowing preoperatively, 54 (90\%) were swallowing the on 1st postoperative day, 57 (95\%) by postoperative Day 3, and all of them by Day 6 .

The majority of patients (67 patients, 93\%) experienced improvement of symptoms shortly after the surgical procedure. Five patients continued to be symptomatic but did not develop new deficits. On long-term follow-up, all patients continued to show improvement, and no delayed procedure-related complications were reported.

\section{Discussion}

The endonasal route takes advantage of a natural anatomical corridor to approach a deep-seated area such as the CVJ. Reporting the current review of the literature and combining the results of the available studies, we provide an overview of the current role of endoscopic endonasal surgery in the treatment of congenital or acquired pathology of the CVJ. According to our results, this approach is effective in relieving neural compression and improving neurological function in the majority of patients (Fig. 2). Procedure-related complications are observed in a small number of patients and are within the accepted range for this type of pathology. In particular, meningitis, which is one of the more feared complications of the transoral approach and is likely related to surgical field contamination with saliva and oral bacterial flora, has been found to be a minor risk in transnasal surgery. Only 1 case of meningitis in 72 patients was recorded. Of note, although this procedure is typically thought of as extradural, there was an $18 \%$ observation of intraoperative CSF leak. However, this approach allows the surgeon to perform an effective dural repair, as demonstrated by the small incidence of postoperative CSF leak (4.2\%).

Our results highlight one of the main advantages of the endonasal route, which is the lower rate of postoperative dysphagia and respiratory complications. Most patients were extubated in the immediate postoperative period, and $95 \%$ were swallowing by the 3rd postoperative day. These findings compare favorably to those of studies evaluating the transoral approach, which have reported a need 

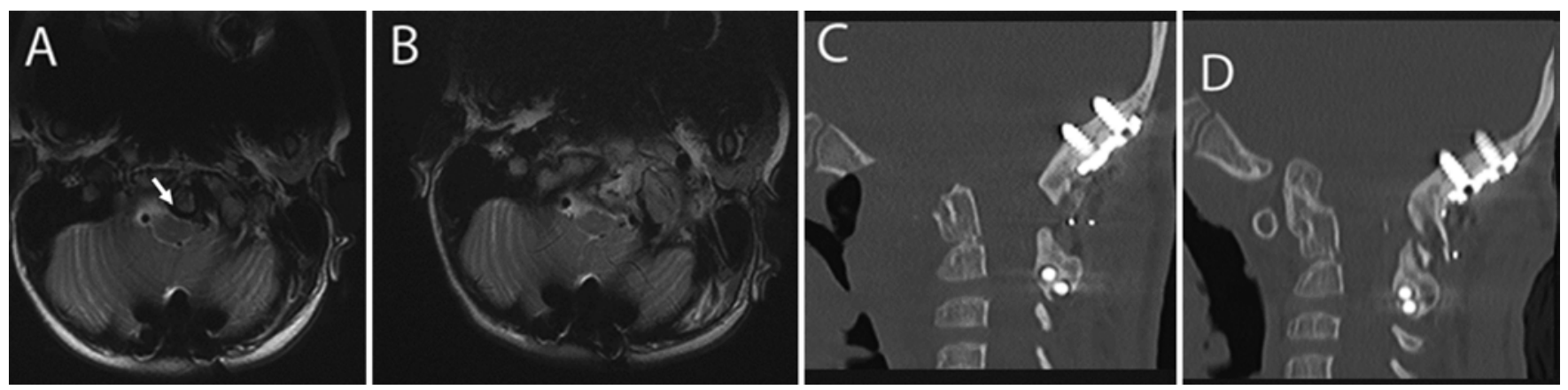

FIG. 2. Preoperative (A and C) and postoperative (B and D) axial T2-weighted MR images ( $A$ and $B$ ) and sagittal CT reconstructions ( $C$ and $D)$ of an endonasal odontoid resection in an 8-year-old girl with medullary compression (arrow).

of enteral feeding in $90 \%-100 \%$ of patients. ${ }^{16,18}$ According to a recent anatomical study, the lower incidence of postoperative dysphagia with the endonasal approach is likely related to the lower density of neuronal elements from the pharyngeal plexus above the palatal plane. ${ }^{15}$

The cumulative experience with the endoscopic endonasal approach allows a direct comparison with the traditionally used transoral-transpharyngeal approach and the recently introduced transcervical approach for the treatment of CVJ pathology. ${ }^{3}$ Few studies have compared directly the different approaches. Raper et al. found no difference in the rate of successful complete odontoidectomy between the transoral and endonasal approaches. ${ }^{14}$ However, the time to extubation and oral feeding was significantly shorter in the endonasal group. Similarly, Ponce-Gómez and colleagues reported their own series of patients treated using both approaches and found comparable rates of neurological improvement after odontoidectomy, with less time to extubation and oral feeding, as well as shorter hospital stay in the endonasal group. ${ }^{13}$

However, the direct comparison of transoral and endonasal endoscopic approaches should be looked at carefully. The studies reporting both approaches may be affected by selection bias, due to a different patient population and indications. In our opinion and in agreement with other authors, the endoscopic endonasal approach, rather than an alternative, should be considered a complementary approach to the standard transoral-transpharyngeal route. ${ }^{11}$ Some patient-related factors can help determine the most suitable approach. For instance, in patients with micrognathia, macroglossia, or limited oral aperture $(<3 \mathrm{~cm})$, the transoral approach is more challenging. ${ }^{2,11}$ The experience of the surgical team should also be considered, and the endoscopic endonasal approach should be used in carefully selected cases only by operators with extensive experience with this technique.

Our study has some limitations. There is a potential publication bias, as studies reporting good outcomes are more likely to be published. In addition, the study heterogeneity was considerable, as we included series from different centers and different patient populations. The quality of the evidence presented here depends on the quality of the included studies, which is affected by the small number of patients and their retrospective nature. Nevertheless, this literature review provides useful data and a starting point to further define the role of endoscopic endonasal surgery in the treatment of CVJ pathology.

\section{Conclusions}

The endonasal endoscopic approach for the treatment of pathology of the CVJ is an effective treatment option for carefully selected patients. In general, it constitutes a safe approach in experienced hands. This approach should be considered as complementary rather than an alternative to the traditional transoral-transpharyngeal approach.

\section{References}

1. Alfieri A, Jho HD, Tschabitscher M: Endoscopic endonasal approach to the ventral cranio-cervical junction: anatomical study. Acta Neurochir (Wien) 144:219-225, 2002

2. Choudhri O, Mindea SA, Feroze A, Soudry E, Chang SD, Nayak JV: Experience with intraoperative navigation and imaging during endoscopic transnasal spinal approaches to the foramen magnum and odontoid. Neurosurg Focus 36(3):E4, 2014

3. Dasenbrock HH, Clarke MJ, Bydon A, Sciubba DM, Witham TF, Gokaslan ZL, et al: Endoscopic image-guided transcervical odontoidectomy: outcomes of 15 patients with basilar invagination. Neurosurgery 70:351-360, 2012

4. Duntze J, Eap C, Kleiber JC, Théret E, Dufour H, Fuentes S, et al: Advantages and limitations of endoscopic endonasal odontoidectomy. A series of nine cases. Orthop Traumatol Surg Res 100:775-778, 2014

5. Gempt J, Lehmberg J, Grams AE, Berends L, Meyer B, Stoffel M: Endoscopic transnasal resection of the odontoid: case series and clinical course. Eur Spine J 20:661-666, 2011

6. Gladi M, Iacoangeli M, Specchia N, Re M, Dobran M, Alvaro $\mathrm{L}$, et al: Endoscopic transnasal odontoid resection to decompress the bulbo-medullary junction: a reliable anterior minimally invasive technique without posterior fusion. Eur Spine J 21 (Suppl 1):S55-S60, 2012

7. Goldschlager T, Härtl R, Greenfield JP, Anand VK, Schwartz TH: The endoscopic endonasal approach to the odontoid and its impact on early extubation and feeding. J Neurosurg 122:511-518, 2015

8. Iacoangeli M, Gladi M, Alvaro L, Di Rienzo A, Specchia N, Scerrati M: Endoscopic endonasal odontoidectomy with anterior $\mathrm{C} 1$ arch preservation in elderly patients affected by rheumatoid arthritis. Spine J 13:542-548, 2013

9. Kassam AB, Snyderman C, Gardner P, Carrau R, Spiro R: The expanded endonasal approach: a fully endoscopic transnasal approach and resection of the odontoid process: technical case report. Neurosurgery 57:E213, 2005

10. Lee A, Sommer D, Reddy K, Murty N, Gunnarsson T: Endoscopic transnasal approach to the craniocervical junction. Skull Base 20:199-205, 2010

11. Mazzatenta D, Zoli M, Mascari C, Pasquini E, Frank G: Endoscopic endonasal odontoidectomy: clinical series. Spine (Phila Pa 1976) 39:846-853, 2014 
12. Nayak JV, Gardner PA, Vescan AD, Carrau RL, Kassam AB, Snyderman $\mathrm{CH}$ : Experience with the expanded endonasal approach for resection of the odontoid process in rheumatoid disease. Am J Rhinol 21:601-606, 2007

13. Ponce-Gómez JA, Ortega-Porcayo LA, Soriano-Barón HE, Sotomayor-González A, Arriada-Mendicoa N, GómezAmador JL, et al: Evolution from microscopic transoral to endoscopic endonasal odontoidectomy. Neurosurg Focus 37(4):E15, 2014

14. Raper DMS, Komotar RJ, Starke RM, Anand VK, Schwartz TH: Endoscopic versus open approaches to the skull base: a comprehensive literature review. Op Tech Otolaryngol 22:302-307, 2011

15. Van Abel KM, Mallory GW, Kasperbauer JL, Moore EJ, Price DL, O'Brien EK, et al: Transnasal odontoid resection: is there an anatomic explanation for differing swallowing outcomes? Neurosurg Focus 37(4):E16, 2014

16. Van Gompel JJ, Morris JM, Kasperbauer JL, Graner DE, Krauss WE: Cystic deterioration of the C1-2 articulation: clinical implications and treatment outcomes. J Neurosurg Spine 14:437-443, 2011

17. Wu JC, Huang WC, Cheng H, Liang ML, Ho CY, Wong TT, et al: Endoscopic transnasal transclival odontoidectomy: a new approach to decompression: technical case report. Neurosurgery 63 (1 Suppl 1):ONSE92-ONSE94, 2008

18. Yadav YR, Madhariya SN, Parihar VS, Namdev H, Bhatele PR: Endoscopic transoral excision of odontoid process in irreducible atlantoaxial dislocation: our experience of 34 patients. J Neurol Surg A Cent Eur Neurosurg 74:162-167, 2013

19. Yen YS, Chang PY, Huang WC, Wu JC, Liang ML, Tu TH, et al: Endoscopic transnasal odontoidectomy without resection of nasal turbinates: clinical outcomes of 13 patients. J Neurosurg Spine 21:929-937, 2014

20. Yu Y, Wang X, Zhang X, Hu F, Gu Y, Xie T, et al: Endoscopic transnasal odontoidectomy to treat basilar invagination with congenital osseous malformations. Eur Spine J 22:1127-1136, 2013

\section{Author Contributions}

Conception and design: all authors. Acquisition of data: MoralesValero, Serchi. Analysis and interpretation of data: all authors. Drafting the article: Van Gompel, Morales-Valero, Serchi. Critically revising the article: all authors. Reviewed submitted version of manuscript: all authors. Approved the final version of the manuscript on behalf of all authors: Van Gompel. Study supervision: Van Gompel, Zoli, Mazzatenta.

\section{Correspondence}

Jamie J. Van Gompel, Department of Neurologic Surgery, Mayo Clinic, 200 First St. SW, Rochester, MN 55905. email: vangompel.jamie@mayo.edu. 